\title{
Managing Deep Intercultural Training Exercises
}

\author{
Martha Maznevski, International Institute of Management Development, Switzerland
}

IN THE "STEP ON JESUS" EXERCISE, the instructor asks students to write the letters J-E-S-U-S on a piece of paper, reflect, then step on the paper. The exercise is a powerful mechanism for demonstrating the relationship between physical artifacts, the symbolic meaning they develop and the importance of that meaning for social identity. Understanding this artifact-to-identity link is important for understanding the nature of culture and developing empathy with people from other cultures, two key aspects of effective international management.

At the same time, each learner's social identity and relationship to the symbols being used to illustrate the lesson affect the learner's openness to developing cultural knowledge and empathy. Exercises that illustrate the deep artifact-identity link, like the "step on Jesus" exercise, need to be selected and conducted with sensitivity to the environment and guided by social identity perspectives.

\section{Cultural Basics: Artifacts Become Symbols with Formalized Meaning}

The most important construct about the social context of international business is culture: the system of shared values and norms among a specific group of people. Culture is often analyzed at several levels (Schein, 1984) with artifacts being visible manifestations, and underlying values, norms and assumptions being less visible, even to the people in the culture. All people belong to multiple cultural groups with shared values, norms and assumptions. These groups may be related to nation, region, religion, school, profession, company, football team, music genre and so on. Usually, at any one time, one cultural context dominates a person's norms, values and assumptions.

Artifacts take on symbolic meaning when a group repeatedly uses them in the same situation, and they denote meaning beyond their objective characteristics. For example, certain Greek letters symbolize one thing to physicists, another to philosophy scholars and something else to members of sororities and fraternities in US universities. Like all aspects of culture, their meaning is passed on from generation to generation.

People within a culture are often unaware that a symbol meaningful to them is not meaningful in another cultural context, and vice versa. The link between artifacts and symbols can seem arbitrary when viewed from the outside, but it is highly meaningful to a group's members. If managers are to be able to work effectively in multiple cultures, they must understand and empathize with the nature of this link.

The "step on Jesus" exercise is intended to demonstrate this link. It directs students to reflect on how the cultural context shapes the meaning that someone gives to the symbol, and the effect of that symbol on members of their culture. It asks learners to question their taken-forgranted assumptions about the links between artifacts and symbols.

So far, so good.

\section{Enter Identity}

If culture were only about an objective, dispassionate mapping of artifacts to symbols such exercises would never raise controversy.

However, culture also creates identity. Individuals feel a bond with others in their cultural group and define themselves according to the group. When group identity is strong, members are willing to follow the norms of the group and sacrifice for the group. In return, the group provides social meaning and support to its members, ranging from physical survival to emotional support.

Self-identity is a cognitive schema of knowledge about oneself. Social identity is the aspect of this cognitive schema associated with belonging to cultural and other groups. Social identities both reduce uncertainty (cognitive aspect) and increase self-esteem (motivational aspect). Social identities differ in salience, distinctiveness, and prestige (Ashforth \& Mael, 1989). A strong (deep) identity is highly salient, distinctive, and prestigious.

A salient identity is readily accessible to aid interpretation and action. National or religious identities may be accessible most of the time, while an identity with a sports team may be accessible only when the team is playing. An identity is distinctive when it is unique. A technology engineer in a services firm may have a stronger professional identity than the service providers do. An identity is prestigious when it has in the beholder's eyes - high status. For people in Canada or the United States, cultural identity with Western Europe is often seen as more prestigious than cultural identity with other parts of the world.

Beyond linking artifacts with symbols, the "step on Jesus" exercise illustrates the nature and power of social identity from culture: for most 
people who have a strong Christian identity (i.e., for whom Christianity is salient, distinctive and prestigious), stepping on Jesus goes against the norms, values and social commitment associated with Christianity. The feeling of discomfort powerfully demonstrates that this identity is not only related to objective links of artifacts to symbols, but is also deeply emotional for some people. The empathy required to see this lesson is very important for cross-cultural management. The "step on Jesus" exercise helps students learn the entire artifact-identity connection and its implications for different groups.

Okay, more complex, but still so far, so good.

\section{Threats to Identity Can Block or Negate Learning}

When we face a situation that is interpreted negatively by our identity schema, we feel a threat to our sense of self. At minimum, this threat decreases our self-esteem. Handling multiple identities increases psychological work (Fitzsimmons, 2014), so if we cannot resolve conflicting identities, we are tempted to reject identities that threaten ones we hold deeply.

As international business professors, we may argue that understanding such an identity threat is a very important point of this lesson. However, the catch is this: learning under identity threat hinders learning in general (Sherman et al., 2013). The stronger the identity threat, the more it hinders learning. If we take a look at the "step on Jesus" exercise as a social identity threat, we start to see how it can be damaging.

The exercise threatens a particular social identity: Christianity. For many Christian students, this is an identity that is salient, distinctive and prestigious. It is salient because it covers so many aspects of life and was likely developed during a very formative period of the student's life. It is distinctive because it dictates a set of norms and values that

\section{SB In order to develop as international managers,} students must learn about the deep and pomerful
relationship between artifacts and cultural identity.

are different from mainstream society. And it is prestigious because it identifies a sense of worthiness not just in this life but also in a life after. If the identity is very deep and strong, then a threat to the identity is also deep and strong, and raises a large barrier to learning.

Moreover, the request to "step on Jesus" comes out of the norms of another potentially strong culture - the academic culture. For an undergraduate, this identity could have high salience (especially during class sessions), distinctiveness (universities are set aside from the rest of society) and prestige (a university education is considered aspirational). A Christian student in this exercise could easily feel conflict between two important social identities: an academic identity with a set of norms dictating that the student comply with the professor's instructions to "step on "Jesus" and a Christian identity with a set of norms dictating that she or he comply with the church's norms to respect and hold sacred "Jesus." Managing multiple identities takes a psychological toll (Fitzsimmons, 2014). Therefore, if both identities are felt strongly, the situation could become volatile. There would be a strong need to resolve the uncertainty, and the most likely way of doing this is to segment the identities, for example by exiting the situation.

\section{Facilitating Learning about the Artifact-Identity Link}

In order to develop as international managers, students must learn about the deep and powerful relationship between artifacts and cultural identity. The research on cognition and identity provides advice about how to help students learn this concept.

First, the general environment in the class and the educational institution should support multiple identities. It should be "okay" for people to belong to different groups, and students should be encouraged to learn about each others' identities. Professors, too, should be aware of their own scientific subculture, and reflect upon the assumptions implied within this subculture and its potential unintended consequences for students' learning. All students — and professors — will experience identity threats from time to time; however, an environment of self-affirmation ("I may disagree with you, but I still think you're a good person") gives students the strength to manage the threats without them blocking learning.

Second, the professor should sequence a series of artifact-identity exercises from ones that are likely to be less strong for students, to ones that are stronger. For example, the professor could start with the relationship between artifacts and identity for Greek letters as discussed above. These cultures are typically learned later in life and are weaker than religion, while still being strong enough (e.g., both prestigious and distinctive) to evoke emotional responses and the realization that others

may not hold the same assumptions. The bank HSBC has a popular series of advertisements that illustrate these relationships well. Students therefore learn the basic lesson about the relationship between artifacts and identity, before having their own strongest identities threatened.

Whenever teaching about the relationship between artifacts and identity, the professor should ensure there is enough time for a thorough discussion and should be prepared to lead this discussion carefully, using language and processes that validate students' identities. The links among artifacts-symbols-culture-identity should be drawn out explicitly. Different individuals' emotions should be surfaced and 
shared, demonstrating that artifact-identity links vary among individuals. This discussion is not the time to disagree with students' values, or to allow students to disagree with each others' values. The discussion should keep the focus on helping students understand the link from artifacts to identity and their implications in different cultural groups.

Finally, the professor should have a "Plan B" and be prepared for things to go wrong and become volatile. Wars break out between and within countries, companies' international customer relationships and cross-border alliances dissolve because of lack of understanding each others' symbols and identity. In the classroom, this kind of misunderstanding usually manifests itself in more simple fight (arguing with each other) or flight (leave the class, avoid the class) behavior, so it is not usually dangerous; however, it is certainly a missed opportunity for learning. When the professor feels that the discussion is heading into a danger zone, the first thing to do is acknowledge this explicitly, and pause for reflection, e.g., "Let's pause for a minute before we go further down this path. Please take a moment individually, and write down exactly what you are feeling right now and why you feel it."This allows students to reflect on their own identity and how it is related to the current situation. Then the students can take a few minutes to discuss in pairs or small groups their reactions; this facilitates selfaffirmation and a more supportive environment for managing identity threat. The professor should then validate the controversy by linking it to the artifact-identity relation, e.g., "I know this discussion is emotionally charged right now, and you are feeling many different things. This is a good illustration of exactly what we are learning about today - that culture is not just about how you hand over business cards, it goes much deeper. Let's try to understand why this discussion is so difficult, and that will help us understand culture better too." The professor should be prepared to abandon the rest of the exercise and instead focus on debriefing the volatile situation. In fact, the volatile situation is more "real" than the exercise and provides an even better illustration of the artifact-identity link.

\section{"Step on Jesus": Dangerous but Important Territory}

Exercises that help students learn the profound relationships among artifacts, symbols, culture and identity are extremely important in the international business class repertoire. Without them, students may miss key self-awareness and empathy lessons that are critical for effective international work. Rather than avoid these exercises, professors should apply conceptual rigor to preparing and discussing them appropriately. Preventing severe identity threat and facilitating the development of new knowledge about alternative artifact-identity relationships turns such exercises into powerful learning experiences.

\section{References}

Ashforth, B. E., \& Mael, F. 1989. Social identity theory and the organization. Academy of Management Review, 14(1): 20-39.

Fitzsimmons, S. R. 2014. Multicultural employees: A framework for understanding how they contribute to organizations. Academy of Management Review, 38(4): 525-549.

Maznevski, M. L., \& Lane, H. W. 2004. Shaping the global mindset: Designing educational experiences for effective global thinking and action. In N. Boyacigiller, R. Goodman, \& M. Phillips (Eds), Crossing cultures: Insights from master teachers: 343-371. London: Routledge.

Schein, E. H. 1984. Coming to a new awareness of organizational culture. Sloan Management Review, 25(2): 3-16.

Sherman, D. K., Hartson, K. A., Binning, K. R., Purdie-Vaughns, V., Garcia, J., Taborsky-Barba, S., Tomasetti, S., Nussbaum, D., \& Cohen, G. 2013. Deflecting the trajectory and changing the narrative: How self-affirmation affects academic performance and motivation under identity threat. Journal of Personality and Social Psychology, 104(4): 591-618.

Martha Maznevski (email: Martha.Maznevski@imd.org) is Professor of Organizational Behavior and International Management at IMD, International Institute for Management Development at Lausanne, Switzerland. Her current research focuses on dynamics of highperforming teams and networks in multinational organizations, and managing people in global complexity. Martha Maznevski co-developed the Cultural Perspectives Questionnaire, an instrument that measures individuals' cultural orientations and is widely used as a diagnostic tool in global teams and organizations. 